\title{
Trabalhonecessário
}

Issn: 1808 - 799X

ano 13, número $21-2015$

\section{ESTADO E EDUCAÇÃO POPULAR NA REVOLUÇÃO PORTUGUESA}

Rui Canário ${ }^{1}$

\section{Resumo}

Este artigo dá continuidade a uma análise das dinâmicas de educação popular na Revolução Portuguesa de 25 de Abril de 1974, com base na contraposição analítica dos conceitos de autonomia e heteronomia das classes trabalhadoras. No caso presente o foco analítico incide sobre as iniciativas heterónomas, por parte do Estado, com intencionalidade educativa, no período de 1974-1976. Três ações são consideradas como as mais significativas: a Campanha de Dinamização Cultural (da iniciativa do Movimento das Forças Armadas), o programa SAAL (Serviço Ambulatório de Apoio Local) e o Programa de ação da DGEP (Direção Geral de Educação Permanente), sendo os dois últimos da iniciativa dos Governos Provisórios. Conclui-se que a ação heterónoma do estado pode manter-se num quadro de total exterioridade em relação aos movimentos sociais (caso da Campanha de Dinamização Cultural) mas também pode revelarse fecunda quando combinada com a iniciativa popular, criam-se então condições para que processos de educação popular se concretizem. No caso do Programa SAAL verifica-se um processo de aliança entre moradores pobres e arquitetos, na resolução de problemas habitacionais. Por fim, o Programa de Ação da DGEP

\footnotetext{
1 Professor Catedrático da Universidade de Lisboa. Instituto de Educação da Universidade de Lisboa - rui.f.canario@netcabo.pt
}

TrabalhoNecessário - www.uff.br/trabalhonecessario; Ano 13, № 21/2015. 


\section{Trabalhonecessário}

Issn: $1808-799 X$

ano 13 , número $21-2015$

materializa a aposta de um serviço educativo estatal no desenvolvimento de processos de educação popular autogerida.

Palavras-chave: educação popular; movimentos sociais; autonomia e heteronomia das classes trabalhadoras.

\section{Abstract}

This article analyzes the dynamics of popular education in the Portuguese Revolution of April 25, 1974, based on analytical contrast between the concepts of autonomy and heteronomy of the working classes. This analysis focuses on the State heteronomous initiatives with educational intentionality from 1974 to 1976. Three initiatives are considered to be the most significant: the Cultural Promotion Campaign (an initiative of the Armed Forces Movement), the SAAL (Local Support Outpatient Service) and DGEP action program (General Directorate of Permanent Education), the latter two being the initiative of the Provisional Governments. It can be concluded that the state heteronomous action can be performed totally externaly in relation to social movements (as is the case of the Cultural Promotion Campaign), but can also prove fruitful when combined with the popular initiative, thereby creating the conditions for the implementation of popular education processes. In the case of SAAL there is an alliance between poor residents and architects with a view to solving housing problems. Finally, DGEP Action Program materializes the investment of a state service in the development of self regulated popular education processes.

Key Words: popular education; social movements; autonomy and heteronomy of working classes 


\section{Trabalhonecessário}

Issn: $1808-799 X$

ano 13, número $21-2015$

Em textos recentemente publicados (Canário, 2013; 2014), tenho vindo a desenvolver um esforço analítico de clarificação do sentido do uso, ou usos, da expressão "educação popular". Tenho como referência o período histórico de intensa mobilização popular iniciado com o golpe militar do 25 de Abril de 1974 e concluído com o contragolpe de 25 de Novembro de 1975 que, ao representar o início de uma fase de "normalização", selaria a derrota da revolução portuguesa.

Para compreender as dinâmicas educativas inerentes às dinâmicas sociais então vividas, o "caso" da Revolução Portuguesa de Abril disponibiliza informação empírica que torna particularmente evidente a pertinência analítica dos conceitos de autonomia e heteronomia.

A contraposição entre autonomia e heteronomia das classes trabalhadoras permite distinguir entre "educação popular", baseada num processo coletivo e autónomo de autoaprendizagem, e a "educação do povo", tutelada a partir de uma ação heterónoma conduzida pelo Estado. Num processo de educação "popular", as classes trabalhadoras assumem-se como sujeitos e protagonistas da História; na "educação do povo" as classes trabalhadoras são encaradas e tratadas como objetos de mudança.

Pretendo aqui dar continuidade ao trabalho que empreendi, apresentando as principais iniciativas educativas que no período revolucionário tinham como alvo o "povo" e eram oriundas da esfera do Estado. Parto do pressuposto de que, apesar de forte crise, o Estado não desapareceu em Portugal em 74/75 (Cerezales, 2003; Chilcote, 2014).

Retomarei como eixo estruturante a distinção entre a orientação da "alfabetização" e a orientação do "poder popular", estabelecida por Steve Stoer (1986) numa obra que é já um clássico do estudo das políticas educacionais em Portugal, no período pós 25 de Abril. Estão em causa duas estratégias para a revolução portuguesa: 


\section{Trabalhonecessário}

Issn: $1808-799 X$

ano 13, número $21-2015$

- A perspetiva da "alfabetização", que remete para uma estratégia assente na "dominação do aparelho de estado, na preparação duma direção centralizada da revolução, com o MFA a agir como força de vanguarda" (Stoer, 1986, 171), no sentido de uma mobilização educacional baseada na ação heterónoma do estado e materializada em ações e programas de educação do povo (ensino e esclarecimento).

- A perspetiva de "poder popular", que "assentava na noção dum movimento social autónomo em relação ao Estado, nas noções de dualidade de poder e de construção duma alternativa revolucionária através de órgãos locais" (Stoer, 1986, 171). Em termos de mobilização educacional, estava em questão uma pedagogia da revolução em que eram protagonistas as classes trabalhadoras, através das comissões de base, num processo em que se confundiam a forma e o conteúdo, os objetivos e os meios.

Tomarei como ações mais significativas da ação educativa heterónoma do Estado a Campanha de Dinamização Cultural conduzida pelo MFA; o Programa SAAL (Serviço Ambulatório de Apoio Local) da iniciativa dos Governos Provisórios; e, finalmente, o Programa de Ação da DGEP (Direção Geral da Educação Permanente) no período de nove meses correspondentes à vigência do VI Governo Provisório.

\section{A Campanha de Dinamização Cultural}

Como informa o Boletim do MFA (FERREIRA, 1975), durante o período revolucionário desenvolveu-se e estendeu-se a todo o país a "Campanha de Dinamização Cultural e Esclarecimento Cívico" como imperativo de "ir ao povo" numa missão de denúncia e esclarecimento, quer do que fora o regime ditatorial, 


\section{Trabalhonecessário}

Issn: $1808-799 X$

ano 13, número $21-2015$

quer das razões do 25 de Abril. No âmbito desta campanha realizaram-se cerca de 2000 sessões, "aproveitando-se a existência de Regiões Militares que mobilizaram as suas unidades para o efeito"(p. 413). O ponto de partida para esta intervenção era um diagnóstico muito sombrio sobre uma realidade "triste e desoladora" do país, onde impera o "obscurantismo, o analfabetismo, o atraso social, a doença, a miséria, ou seja, o conjunto de formas através das quais não há um mínimo de dignidade humana"(p. 420). Como nota Luísa Oliveira (2004, p. 19), esta campanha inscreve-se num conjunto de experiências históricas de "idas ao povo" cuja matriz remonta ao populismo russo. Na sua génese, a organização e execução da Campanha de Dinamização Cultural assenta numa conceção vanguardista do MFA que transpõe para a "metrópole" a Ação Psicossocial utilizada na guerra colonial. Segundo Salgado Matos, citado por Sónia Almeida (2009, p. 86) "estas campanhas eram a aplicação a Portugal dos métodos de guerra psicológica usados na Guerra Colonial".

A Campanha de Dinamização Cultural foi tutelada pela $5^{\text {a }}$ Divisão do Estado Maior das Forças Armadas e terminou com o golpe militar de 25 de Novembro de 1975, embora algumas equipas possam ter permanecido no terreno até 1976 (Almeida, 2009). A perspetiva paternalista e redentora que preside a esta iniciativa de dinamização cultural está bem expressa quando se apresenta como fundamentos por um lado, a dificuldade decorrente da inexistência de "veículos transmissores da ideologia revolucionária", conjugada, por outro lado, com a necessidade de "rapidamente arrastar as camadas mais imobilistas e tradicionais e condicionadas pelos fatores de obstrução tradicionais" (Correia, sd, p.9). Segundo um elemento das brigadas de terreno, citado por Sónia Almeida (2009):

"Nós, ao procurar lançar estas campanhas, não pretendemos, de modo algum, solucionar problemas, bem sentidos pelas 


\section{Trabalhonecessário}

Issn: $1808-799 X$

ano 13, número $21-2015$

populações do interior, mas, fundamentalmente, acordá-los para eles e fazê-los sair da apatia em que sempre viveram e trazer mesmo a estas pessoas o significado do 25 de Abril." (p. 62)

$\mathrm{Na}$ conferência de imprensa em que são apresentados os objetivos do designado "Programa de Dinamização Cultural", aponta-se a finalidade de estabelecer uma rede que seria "a base de uma futura vida cultural portuguesa", através de uma ação que se pretende de descentralização, alicerçada na:

“(...) criação de comissões regionais em todo o país, comissões regionais essas que se subdividirão em comissões distritais, as quais integrarão todos os organismos culturais existentes naquela região para além dos organismos de Estado que possam colaborar nestas campanhas e evidentemente as Forças armadas." (p. 79)

Assim se caminharia no sentido de "criar centros culturais na Província", a partir de um esquema organizativo apresentado num organigrama que no topo inscreve o Chefe do Governo e o Chefe de Estado Maior das Forças Armadas e na base as subcomissões (Almeida, 2009, p. 79-82). Qualquer propósito que em termos de conteúdo possa ser definido como "descentralizador" é claramente contrariado pela forma assumida pelo programa.

A realização de eleições para a Assembleia Constituinte era um dos pontos mais importantes do programa político do MFA. No entanto, estas eleições prenunciavam-se como uma ameaça à legitimidade revolucionária se, como veio a acontecer, os resultados fossem favoráveis aos partidos conservadores. A entidade que tutelava a Campanha de Dinamização Cultural era no mínimo bastante reticente e pessimista quanto à realização de eleições. Paradoxalmente, adotava-se a posição do regime deposto segundo a qual o povo não estaria preparado para eleições democráticas. Como se pode ler no Boletim do MFA (Ferreira, 1975, p. 49): 


\section{Trabalhonecessário}

Issn: $1808-799 X$

ano 13, número $21-2015$

"O estado de dominação a que estão sujeitas as classes trabalhadoras, em especial nas zonas rurais, e a ainda pouco madura consciência da sua própria situação de exploração e de opressão, tornam estas classes manobráveis num processo eleitoral conduzido de forma alienante, e para o qual não existe a necessária prática política devido ao obscurantismo em que se viveu durante quase meio século."

Com base num esclarecimento prévio, a Campanha de Dinamização Cultural deveria instituir-se como ferramenta para o povo poder fazer uma opção consciente. Como afirmava em entrevista um dos responsáveis (Correia, 1975, p.39):

"Pretende-se, pois, pôr as pessoas a um nível de esclarecimento que permita que o aparecimento das linhas programáticas dos partidos seja estudado, cuidadosamente analisado e, então sim, que a escolha seja fruto de uma opção consciente."

A antecipação pessimista dos resultados das eleições - que viria a revelarse fundada - teria mesmo conduzido o MFA, através da $5^{\mathbf{a}}$ Divisão, a fazer a defesa do voto em branco, que funcionaria como a expressão de um voto no próprio MFA. Não obstante, os resultados vieram efetivamente a confirmar as piores expectativas, na medida em que perante eleições largamente participadas $(91,7 \%)$, foram precisamente as forças conservadoras as que obtiveram vitória inequívoca e o voto em branco expressão mínima (6,94\% para os votos brancos e nulos). Como afirma Sónia Almeida (2009, p. 237), a orientação política do MFA foi claramente contrariada e "a partir deste momento, o MFA transforma-se numa força de oposição". Num balanço a posteriori, é possível colocar como hipótese pertinente que a Campanha de Dinamização Cultural tenha tido efeitos contraproducentes e perversos, funcionando numa lógica de vacina e não de inculcação dos ideais revolucionários. 


\section{Trabalhonecessário}

Issn: $1808-799 X$

ano 13, número $21-2015$

Organizadas como "operações militares" de curta duração, com pessoal impreparado e "reforçado" por artistas diversos, as ações de dinamização cultural condenavam-se à qualidade de ações de propaganda política de quase nula eficácia, apesar da sua pretensa "função redentora" (Veiga, 2002, p. 72).

Um bom exemplo deste tipo de iniciativas foi a "Operação Verdade" (Ferreira, 1975, p. 406), desencadeada no Alto Minho entre 31 de Janeiro e 9 de fevereiro de 1975 (dez dias) e protagonizada por militares do "Regimento de Caçadores Para-quedistas e da Base Aérea $n^{\circ} 3^{3}$, acompanhados "para animação cultural" pela "Banda da Força Aérea, pela Comuna [grupo de teatro] e por "uma parelha de palhaços". Constituíram-se em oito equipas, formadas, cada uma, por dois oficiais, dois sargentos e dois praças, que atuavam numa área vasta e populosa, "estacionando diariamente numa freguesia", "detetando os problemas existentes" e "esclarecendo o Programa do MFA".

Acontece que a ação destas equipas se baseava no pressuposto de uma população em défice, o que inviabiliza uma ação para a autonomia e induz uma pedagogia transmissiva e bancária (conceitos de Paulo Freire):

\footnotetext{
"Saídos da noite fascista, a maioria dos portugueses desta zona vivem num ambiente crepuscular, em que o Sol da verdadeira e plena liberdade só agora começa a surgir, por detrás das nuvens sombrias do obscurantismo cultural e político, do subdesenvolvimento." (Ferreira, 1975, pp. 406/407)
}

\section{O Programa SAAL: uma aliança entre arquitetos e moradores}

O Serviço de Apoio Ambulatório Local (SAAL) tem origem estatal e foi criado em 31 de Julho de 1974, a partir de um despacho conjunto de dois ministérios (Administração Interna e Ambiente). Instituía-se assim um corpo 


\section{Trabalhonecessário}

Issn: $1808-799 X$

ano 13, número $21-2015$

técnico especializado destinado a apoiar as "iniciativas de populações mal alojadas no sentido de colaborarem na transformação dos próprios bairros" (M. Coelho, 1986, p. 621). O SAAL viria a ser praticamente extinto em Outubro de 1976 por decisão do I Governo Constitucional.

Através da memória dos moradores, foi recuperada em obra recente (Baía, 2012) a experiência de interação entre o SAAL e a dinâmica dos movimentos autónomos dos moradores no Bairro da Relvinha, em Coimbra. Trata-se de um caso que ilustra particularmente bem como o processo de intervenção se articulou com o movimento de moradores numa ação que interliga o direito à habitação com o direito à cidade:

"No Bairro da Relvinha, segundo os informantes, a relação [entre técnicos e moradores] foi fraterna e o arquiteto cedeu quanto às alterações propostas pelos moradores ao projeto inicial. Reciprocamente os moradores aceitaram o projeto, que já incluía as propostas de alteração." (Baía, 2012, p. 123)

Como no caso de uma comunidade piscatória imortalizada por uma canção de José Afonso (Índios da Meia Praia), segundo o testemunho de um morador do Bairro da Relvinha, a "luta pela construção das casas" envolveu profundamente os moradores:

"As pessoas a meter tijolo, mulheres, crianças, toda a gente ali a ajudar, foi lindo (...). Foi uma envolvência muito grande. Festas que se fizeram. Foi um dos momentos mais bonitos da história do Bairro da Relvinha." (p. 127).

Um outro testemunho dá conta de um processo que implicou uma colaboração estreita entre moradores e técnicos para concretizar o objetivo comum: 


\section{Trabalhonecessário}

Issn: $1808-799 X$

ano 13, número $21-2015$

"Todos lutaram de mãos dadas para atingir esse objetivo e depois foi o cruzamento de culturas, de diferentes graus académicos, estudantes, jovens de outros países, analfabetos, pessoas sem cultura nenhuma. Toda a gente ali irmanada no mesmo objetivo que era criar a obra. E isso foi enriquecedor." (p. 126)

Assim se institui um processo de criação que se define como uma aprendizagem recíproca. Tal como nos relata um morador, "eles aprenderam connosco e nós aprendemos com eles, quer dizer, foi uma aprendizagem mútua que se teve aqui no Bairro (Baía, 2012 p. 136). Numa síntese feliz, João Baía (2012, p. 168) defende que o tempo do processo revolucionário representou nos bairros um tempo de "esperança e de sonho", por oposição ao "silenciamento e ao medo", característicos da ditadura e da "desilusão e do pessimismo" que marcam o período posterior à chamada "normalização" política que pôs fim ao período revolucionário.

Segundo o principal ideólogo e decisor do programa SAAL (o arquiteto Nuno Portas, na época membro do Governo), em contraste com o modo clássico, a Leste e a Ocidente, de produção de habitação social com base numa racionalidade decidida no interior do aparelho de estado, procurava-se no processo SAAL "romper o alheamento dos moradores em relação a [um] processo de decisão que lhes diz respeito" (Portas, 1986, p. 639). Por oposição à estratégia de deslocalização dos moradores para novos bairros, o programa SAAL baseouse no reconhecimento do seu direito à permanência nos locais de habitação, com a melhoria das respetivas condições. Estava em causa, também, a escolha de uma metodologia de planeamento habitacional feita "de baixo para cima", ou seja, partindo "dos bairros para a totalidade da cidade" (p. 641).

Como refere Brochado Coelho (1986), o programa SAAL correspondeu a uma resposta do aparelho de estado à pressão dos movimentos de moradores que mantiveram a iniciativa com base na criação de formas organizativas próprias 


\section{Trabalhonecessário}

Issn: $1808-799 X$

ano 13, número $21-2015$

(Comissões de Moradores com configurações diversas): "O poder central e a classe política que o habitou não mais fizeram do que aguentar um processo que os excedeu e contrariou" (p. 657). A espontaneidade, a criatividade e a autonomia dos moradores foram os fatores que permitiram manter as forças partidárias como exteriores à sua condução, durante grande parte do processo revolucionário (B. Coelho, 1986, p. 659). Como corrobora Margarida Coelho, os movimentos populares pressionaram o aparelho de estado, forçando a sua modificação, o que justifica que o SAAL possa ser encarado como "uma rutura no Aparelho de Estado" (p.623).

Esta rutura só foi possível porque a intervenção urbana coincidiu com uma dinâmica transversal de aprendizagem inerente a uma relação original entre técnicos e moradores:

"A exclusividade da situação de peritos, usual na Administração Pública clássica, onde os estudos surgem impostos já acabados e sem diálogo, deu lugar à democratização da racionalidade técnica. Isto é, tudo era discutido, explicado, quantas vezes fossem necessárias, sendo as escolhas dos utentes." (M. Coelho, 1986, pp. 628/629)

Segundo Delfim Sardo (2014, p. 28), entre outras competências pedia-se aos técnicos das brigadas SAAL que fossem "pedagogos sociais" que "escutassem as populações e os seus anseios", integrando-os em projeto, e nesse sentido fizessem uma outra arquitetura em que "a encomenda arquitetónica é realizada pelos moradores" organizados em comissões ou associações legalmente constituídas "num processo de mútua aprendizagem". Os arquitetos intervieram nos bairros e essa intervenção modificou-os.

Os movimentos de moradores "sem mestres nem chefes" (Santos, 2014), ou seja autónomos, tiveram uma importância determinante, quer "para as arquiteturas produzidas no âmbito do SAAL, quer para a sequência de 


\section{Trabalhonecessário}

Issn: $1808-799 X$

ano 13, número $21-2015$

circunstâncias posteriores que conduziram à divulgação e à internacionalização da arquitetura portuguesa contemporânea" (Bandeirinha, 2014, p. 46).

Como assinala Margarida Coelho (1986, p. 631), as novas formas de organização local corresponderam a ensaiar novas modalidades de gestão da cidade, articulando a resolução das necessidades básicas com a produção, configurando um "novo modelo de desenvolvimento possível para o país".

Nesta sintética referência ao Programa SAAL, procuramos acima de tudo colocar em evidência o carater educativo intrínseco que the é transversal, apesar de não ser essa a sua principal e expressa finalidade. No caso do programa SAAL, a heteronomia do Estado tornou-se virtuosa na justa medida em que se interligou com projetos protagonizados e autogeridos pelos moradores. Essa pode ter sido, nas palavras de Delfim Sardo (2014, p. 37), " a utopia pragmática mais urgente e poética da Revolução".

\section{DGEP: a aposta na autogestão da educação de adultos}

A experiência a seguir referenciada corresponde a um período muito curto (nove meses de duração entre Outubro de 1975 e Julho de 1976) e está claramente apresentada e documentada num texto (Melo e Benavente, 1978) que procede a um balanço do que foi possível fazer:

"Durante os nove meses que a história lhe concedeu, a DGEP, serviço do Estado, jogou a fundo a carta da autogestão na educação de adultos. Aos grupos locais compete prosseguirem na tarefa que eles próprios começaram." (Melo e Benavente, 1978, p. 135). 


\section{Trabalhonecessário}

Issn: $1808-799 X$

ano 13, número $21-2015$

Este curto período de grande protagonismo da DGEP correspondia nas intenções dos seus responsáveis a uma fase de pesquisa e experimentação que deveria conduzir à elaboração de um plano de atividades. Durante esta fase pretendeu-se implantar no terreno uma parceria entre "a iniciativa pública e a iniciativa popular". Esta modalidade de intervenção educativa heterónoma por parte do Estado, iniciada na vigência do VI Governo Provisório, conheceu um fim abrupto com a entrada em funções do I Governo Constitucional.

Num texto escrito vinte anos depois, Alberto de Melo exprime o seu sentimento de frustração por não ter sido dada continuidade a uma política que ensaiava os seus primeiros passos: ela foi posta de lado porque, no entendimento dos governos subsequentes, esta proposta de ação foi considerada "demasiado 'terceiro - mundista' para um país que preparava a sua candidatura à Europa Comunitária" (Melo, 2012, p. 313). Nesse mesmo texto, o autor reconhece a importância decisiva da influência do pensamento e da prática de Paulo Freire com cuja "clara inspiração" "se lançou nessa altura um programa público de apoio à Educação Popular." (p. 313). A outra e principal força inspiradora da ação da DGEP foi o poderoso movimento social e político protagonizado por órgãos populares de base que constituíram uma rede abrangendo cooperativas, associações populares, empresas em autogestão, comissões de moradores, etc. No interior desta rede, "as atividades de caráter cultural e educativo ocuparam um lugar de eleição. Praticamente todos estes grupos constituíram um comité cultural ou incluíram iniciativas culturais e educativas nos seus planos de ação." (Melo, 2012, p. 383).

Tentando criar os fundamentos para uma nova forma política de agir por parte da administração Pública, a DGEP procurou "colocar o aparelho de Estado ao serviço do cidadão", assumindo a postura de apoiar e facilitar o desenvolvimento da ação instituinte e inovadora dos órgãos populares de base, 


\section{Trabalhonecessário}

Issn: $1808-799 X$

ano 13, número $21-2015$

respondendo às suas solicitações e rompendo assim com uma administração tradicionalmente autoritária, vertical e centralizadora. Seguem-se exemplos de algumas dessas solicitações (Melo, 2012, p. 388):

- $\quad$ Um grupo de mineiros, nos arredores do Porto, organizou um museu sobre o seu trabalho e as suas lutas e pediu um subsídio para editar uma brochura sobre uma das suas greves históricas;

- Uma associação cultural da região de Tomar mobilizou a população local para reconstruir como centro comunitário um velho teatro abandonado. Pedia um animador cultural;

- Uma cooperativa agrícola pediu a colaboração de um historiador e de um arqueólogo para estudo dos vestígios arqueológicos locais;

- Uma cooperativa solicitou cursos de contabilidade e gestão para instruir os seus associados;

- $\quad$ Um grupo do Sindicato dos Ferroviários pretendia fazer entrevistas a trabalhadores ativos e reformados para reescrever uma história dos Caminhosde-Ferro em Portugal;

- Mineiros de uma multinacional solicitaram cursos de francês e inglês, para se poderem corresponder com os colegas estrangeiros;

Desde o início de 1976, foi lançado pela DGEP um programa de bolsas para apoiar atividades de educação popular, com o objetivo de "detetar o maior número possível de organizadores e animadores 'naturais' já em atividade (...), a fim de Ihes dar todo o apoio possível, incluindo apoio financeiro" (Melo e Benavente, 1978, p. 106). Do ponto de vista dos responsáveis da DGEP, "a organização coletiva autogerida criada para fazer face aos múltiplos problemas quotidianos, já era uma forma de (...) auto educação dos adultos"(p. 11). Por intermédio de equipas regionais, de bolseiros, de equipas móveis, haveria um 


\section{Trabalhonecessário}

Issn: $1808-799 X$

ano 13, número $21-2015$

acompanhamento próximo e contínuo destes grupos de base, com a finalidade de intervir "desde que o grupo, uma vez definidas as suas necessidades de ordem educativa e cultural, procurasse satisfazê-las" (p. 11).

Num contexto social e político em que as atividades educativas e culturais tinham a sua origem na iniciativa popular, a DGEP reequacionou o que devia ser a função de um serviço público: respeitar e incentivar a autonomia da base, apoiando o desenvolvimento de projetos, dando-Ihes visibilidade e contribuindo para a sua generalização. Para isso era necessário criar meios de difusão das experiências locais, contribuindo para a criação de redes e criando as condições para dar voz aos grupos de educação auto gerida. É no quadro desta orientação que se situa o projeto editorial do jornal "Viva Voz" cujo primeiro número foi publicado em Julho de 1976. Esta publicação deveria alimentar e alimentar-se de informação sobre as iniciativas de base, de preferência produzida pelos intervenientes locais. É assim que o jornal em editorial do primeiro número se dá a conhecer:

"Não foi portanto o jornal da DGEP que hoje saiu, foi, sim, o portavoz de todas as coletividades, de base local, que queiram ensinarnos o que estão a fazer, que queiram informar o País sobre as suas iniciativas, os seus projetos, as dificuldades e as soluções já encontradas. É uma achega, embora pequena, ao estabelecimento de tal comunicação entre todos, daquela troca entre o que uns sabem e outros querem saber, que queremos seja a educação permanente." (Melo e Benavente, 1978, p. 128).

O projeto de intervenção protagonizado pela DGEP em 75/76, apesar do seu caráter efémero e da sua concretização muito parcial, representou por parte do Estado a primeira tentativa séria de organizar um subsetor do sistema educativo (educação de adultos) numa perspetiva de educação permanente. Como lucidamente reconheceram os responsáveis pela conceção e tentativa de 


\section{Trabalhonecessário}

Issn: $1808-799 X$

ano 13, número $21-2015$

enraizamento de uma política pública ao serviço das iniciativas populares, esta só terá condições mínimas de sucesso "se tiver um apoio forte e constante do exterior do seu próprio ministério, apoio das associações de educação popular, das estruturas municipais eleitas, dos sindicatos, etc." (Melo e Benavente, 1978, p. 17). Quer isto dizer que a ação desenvolvida pela DGEP é indutora e facilitadora do desenvolvimento de atividades educativas populares marcadas pela autonomia, mas só pôde ter existência e significado num contexto social e político em que os órgãos populares de base continuaram a manter alguma vitalidade, mesmo depois do golpe militar de 25 de Novembro de 1975.

Estado, desenvolvimento e educação: fundamentos da corrente de "alfabetização"

Numa perspetiva naturalista, o escritor francês Émile Zola, preocupado com as questões sociais do seu tempo, publicou, nos finais do século XIX, um romance sobre o quotidiano das chamadas "classes perigosas", com o significativo título "A taberna"(L'assomoir"). Neste romance Zola retrata a dissolução moral de uma família operária refém do alcoolismo, salvaguardando no prefácio: "De modo algum se deve concluir que todo o povo é mau, pois as minhas personagens não são más; são apenas ignorantes e acham-se corrompidas pelo meio de rude trabalho e da miséria em que vivem". Eivada de um paternalismo moralista, esta ideia destaca a ignorância como principal atributo das classes trabalhadoras, justificando implicitamente a necessidade de instruir, educar e moralizar o povo como condição necessária. Trata-se de uma perspetiva iluminista e jacobina que estabelece uma articulação direta entre a educação, a razão e o progresso. 


\section{Trabalhonecessário}

Issn: $1808-799 X$

ano 13, número $21-2015$

Acredita-se na necessidade de "educar o povo" através de políticas deliberadas conduzidas pelo estado - marcadas pela heteronomia - com a finalidade de resolver a questão social, pela eliminação do obscurantismo. Esta convicção atravessa as correntes socialistas, libertárias e republicanas que desde meados do século XIX coexistiram em Portugal com um movimento associativo popular de caráter sindical e mutualista. Não admira que ela estivesse presente no contexto da Revolução de Abril, tornando-se uma bandeira do MFA e dos partidos da esquerda.

É, pois, sem surpresa que encontramos esta perspetiva no Programa do PCP (Partido Comunista Português) elaborado com vista às eleições para a Assembleia Constituinte, segundo o qual se verifica no campo da educação "um atraso de dezenas de anos em relação ao progresso da ciência e da pedagogia", daí se concluindo que a "democratização da instrução e da cultura porá fim à ignorância secular das massas trabalhadoras" (PCP, 1975, 46 e 49). Também no domínio da historiografia portuguesa contemporânea se encontra reiteradamente apresentada uma relação causal entre o analfabetismo e o desenvolvimento: " $A$ questão do nível cultural do povo é relevante para a compreensão dos condicionalismos estruturais que entravavam o processo de desenvolvimento económico nacional” (Sousa e Oliveira Marques, 1982, 182). A educação seria portanto o caminho para superar a dupla alienação do povo português manifesta na expressão "Para a igreja e para a taberna convergiam as classes populares" (183).

Foi na sequência da Segunda Guerra Mundial que, como conceito e como prática, a educação de adultos foi colocada no primeiro plano das preocupações educativas mundiais. A Unesco (órgão especializado da ONU) foi a instituição inspiradora que conseguiu convencer as nações do mundo inteiro a inscreverem a educação de adultos nas suas prioridades e programas políticos (BHOLA, 1989). 


\section{Trabalhonecessário}

Issn: $1808-799 X$

ano 13, número $21-2015$

No período dos Trinta Anos Gloriosos (1945-1975) foram lançadas em todo o mundo cerca de meia centena de campanhas de alfabetização de adultos. Estas campanhas de alfabetização em massa foram um produto do fim dos impérios coloniais, correspondendo a esforços para resolver problemas considerados como nacionais e referenciados à problemática do desenvolvimento (CAIRNS, 1989).

É também no quadro destas preocupações nacionalistas e desenvolvimentistas que deverão compreender-se, no período considerado, as políticas de educação de adultos e as campanhas de alfabetização conduzidas no Brasil sob o signo do estigma do analfabeto encarado como "marginal e incapaz" (PAIVA, 2003). Esta maneira de ver só viria a conhecer uma mudança significativa nos anos 60, antes da instauração da ditadura, sob a égide de Paulo Freire.

A Campanha Nacional de Educação de Adultos, desenvolvida durante a ditadura fascista em Portugal, entre 1952 e 1956 correspondia a idênticas preocupações. Inspirava-se claramente no modelo de alfabetização massiva e intensiva proposto pela Unesco e concretizado na América Latina. No caso português, além da eliminação do analfabetismo, visava-se a "construção/inculcação de um quadro de valores consentâneo com a estrutura política, económica, social e ideológica do Estado Novo" (BARCOSO, 2002, 212).

Relembre-se que a Revolução Portuguesa de 1974 se inscreve num contexto de criação de um quadro pós colonial, em que, mercê do atraso no desenvolvimento económico, Portugal aparece como um país periférico próximo e aliado do chamado Terceiro Mundo. É portanto com naturalidade que o Movimento das Forças Armadas (MFA) se auto percecionou como um movimento de libertação nacional, idêntico aos que em África derrotaram o colonialismo português, abrindo o caminho ao 25 de Abril. 


\section{Trabalhonecessário}

Issn: $1808-799 X$

ano 13, número $21-2015$

A importância atribuída às políticas e práticas educativas dirigidas a públicos que são definidos como "pouco escolarizados" tem como base dois pressupostos: o primeiro é a aceitação, de certo modo acrítica, do fenómeno da "escolarização", encarado como uma afirmação inevitável do "progresso" e do "triunfo da razão"; o segundo consiste em considerar os adultos "pouco escolarizados" numa situação de défice, a colmatar através de uma oferta educativa de natureza escolar. A nula ou baixa qualificação escolar é encarada como um défice a preencher e, portanto, como um estigma, na medida em que se estabelece uma articulação linear entre escolarização e desenvolvimento (entendido como sinónimo de crescimento económico) e entre desenvolvimento e progresso. Esta perspetiva é largamente tributária da teoria do capital humano que conduziu a equacionar o analfabetismo como um problema, a um lado, de "atraso" e, a outro, de produtividade e de competitividade, em consonância com uma abordagem economicista e técnica.

A escolarização é assim apresentada como uma necessidade histórica que serve os interesses dos não escolarizados equanto simultaneamente viabiliza a caminhada inelutável no sentido do progresso. Ora, por um lado, não é certo que a promoção da escolarização seja sempre e necessariamente um "bem" para os não escolarizados. Segundo Parajuli (1990), as campanhas de alfabetização podem funcionar como "campanhas muito frutuosas contra os analfabetos". 0 facto de serem concebidas e conduzidas a partir do pressuposto da "ignorância" dos não escolarizados conduz, naturalmente, a deslegitimar os saberes que thes são próprios, contribuindo para desqualificar aqueles que se diz pretender servir.

Por outro lado, é igualmente questionável a "bondade" dos modelos de desenvolvimento próprios das sociedades industriais modernas que encaram a natureza e o trabalho humano como um conjunto de recursos a explorar para maximizar a produção e o lucro. 


\section{Trabalhonecessário}

Issn: $1808-799 X$

ano 13, número $21-2015$

Está em causa o confronto de racionalidades distintas, cuja superioridade só pode ser decidida a partir de critérios políticos e filosóficos e não de critérios técnicos ou científicos. A crítica aos "modelos desenvolvimentistas" é, de resto, bem justificada pelos paradoxos que marcam as sociedades mais desenvolvidas e escolarizadas. A pobreza, o crescimento das desigualdades, o desemprego e a precarização do trabalho são flagelos, cujo agravamento é nas últimas décadas concomitante com os "progressos" da escolarização.

A argumentação que tenho vindo a desenvolver não tem, obviamente, como objetivo pôr em causa a pertinência e os benefícios da literacia. Visa tãosomente recolocar esses benefícios e essa pertinência no quadro de uma visão larga da educação em que esta não desempenhe um papel meramente adaptativo às exigências da ciência, da técnica e da produção nem meramente ortopédico relativamente a grupos considerados como desqualificados (como é o caso dos não letrados).

\section{Heteronomia do Estado: entre a "alfabetização" e o "poder popular"}

Os três exemplos da iniciativa heterónoma do Estado em matéria de educação dos trabalhadores (Campanhas de Dinamização Cultural; Programa do SAAL; Projeto da DGEP) são eloquentes quanto ao caráter fecundo e atual, do ponto de vista heurístico, da contraposição entre dinâmicas educativas desencadeadas pelo Estado em termos de "corrente da alfabetização" ou de "corrente do poder popular", tal como propõe Steve Stoer (1986), cuja obra mantém plena atualidade. Essa contraposição permite ler a relação entre movimentos sociais de base fortes e o grau de autonomia dos trabalhadores no quadro de práticas educativas que se inscrevem num continuum entre a quase 


\section{Trabalhonecessário}

Issn: $1808-799 X$

ano 13, número $21-2015$

absoluta exterioridade do Estado (caso da Campanha de Dinamização Cultural) e a relação virtuosa entre os serviços do Estado e a iniciativa popular, quando a iniciativa heterónoma assume o caráter de uma aposta na educação autogerida (Projeto da DGEP).

Analisando criticamente um Plano Nacional de Alfabetização produzido por um grupo de trabalho governamental em Maio de 1975 e nunca posto em execução, verifica-se que, a acontecer, essa alfabetização assumiria necessariamente "decisões de natureza coerciva em relação aos próprios analfabetos", cada um deles considerado como um "átomo estatístico" (Lima e outros, 1988, p.81). Como refere de forma muito pertinente um outro crítico da "corrente de alfabetização", métodos de intervenção vertical baseados na ideia de esclarecer pessoas "iletradas" e não preparadas, cívica e politicamente, só poderia visar a "espetacular conversão ideológica" de milhares de "vítimas do obscurantismo" (Santos Silva, 1990, pp. 20 e 21).

No caso do Programa SAAL, estamos perante uma iniciativa estatal que à partida não tem quaisquer contornos de intencionalidade educativa, mas cujos efeitos educativos tentámos realçar e que resultam da aliança entre as equipas técnicas do SAAL e os movimentos de moradores pobres, para resolver problemas do quotidiano habitacional. A fecundidade desta articulação e desta contaminação de lógicas de ação varia de caso para caso, o que significa que nada está garantido à partida, ou seja, não há determinismos. Nada é dado e tudo é construído.

Em conclusão, a intervenção estatal só se revela virtuosa quando condicionada e exigida por fortes movimentos sociais que permitem preservar a autonomia dos educandos. Sem autonomia não há educação popular e a autonomia, por definição, não pode ser outorgada. 


\section{Trabalhonecessário}

Issn: $1808-799 X$

ano 13, número $21-2015$

\section{Referências}

ALMEIDA, Sónia (2009). Camponeses, cultura e revolução. Campanhas de Dinamização Cultural e Ação Cívica do MFA (1974-1975). Lisboa: Edições Colibri. BAÍA, João (2012). SAAL e Autoconstrução em Coimbra. Memórias dos moradores do Bairro da Relvinha 1954-1976. Coimbra: 100Luz

BANDEIRINHA, José António (2014). SAAL 1974-2014: Por uma arquitetura. In: Arquitetura e participação. Porto: Casa de Serralves, 43-64

BARCOSO, Cristina (2002). O Zé Analfabeto no cinema. O cinema na Campanha Nacional de educação de Adultos de 1952 a 1956. Lisboa: Educa.

BHOLA, H. S. (1989). L'alphabétisation des adultes : des concepts aux politiques de mise en œuvre. Perspectives, vol. XIX, 4.

CAIRNS, John C. (1989). Les campagnes d'alfhabétisation: bilan et leçons pour l'avenir. Perspectives, vol XIX, 4.

CANÁRIO, Rui (2000). Educação de adultos. Um campo e uma problemática. Lisboa : Educa.

CANÁRIO, Rui (2014). Movimentos de moradores e educação popular na revolução portuguesa de 1974. Trabalho Necessário, ano 12, no 18

CANÁRIO, Rui (2013). Educação Popular e "Questão Social" na modernidade europeia. In: Streck, Danilo e Esteban, Maria Teresa, Orgs. Educação Popular lugar de construção social e coletiva. Petrópolis: Editora Vozes, 334-347.

CEREZALES, Diego Palacios (2003). O poder caiu na rua. Crise de Estado e ações coletivas na Revolução Portuguesa, 1974-1975. Lisboa: ICS

CHILCOTE, Ronald H. (2014). A Revolução Portuguesa. Estado e classes sociais na transição para a democracia. Porto: Edições Afrontamento.

COELHO, Mário Brochado (1986). Um processo organizativo de moradores (SAAL/Norte 1974-1976). Revista Crítica de Ciências Sociais. 18,19 e 20, 645671.

COELHO, Margarida (1986). Uma experiência de transformação no setor habitacional do Estado. SAAL 1974-1976. Revista Crítica de Ciências Sociais, 18, 19 e 20, 619-634.

CORREIA, Ramiro (sd). MFA. Dinamização Cultural. Ação Cívica. Lisboa: Ulmeiro.

FERREIRA, Serafim, Org. (1975) MFA motor da revolução portuguesa. Lisboa: Diabril.

LIMA, Licínio e outros (1988). Reorganização do subsistema de educação de adultos. Documentos Preparatórios III da Comissão de Reforma do Sistema Educativo. Lisboa: Ministério da Educação.

MELO, Alberto e BENAVENTE, Ana (1978). Educação popular em Portugal (1974-1976). Lisboa: Livros Horizonte. 


\section{Trabalhonecessário}

Issn: $1808-799 X$

ano 13 , número $21-2015$

MELO, Alberto (2012). Passagens revoltas. 40 anos de intervenção por ditos e escritos. Lisboa: Associação In Loco, pp. 309-314.

OLIVEIRA, Luísa (2004). Estudantes e povo na revolução. O Serviço Cívico Estudantil (1974-1977). Lisboa: Celta Editora.

PARAJOULI,P. (1990). Politiques du savoir, modèles de développement et alphabétisation. Perspectives, vol. XX, 3

PAIVA, Vanilda (2003). História da Educação Popular no Brasil. S. Paulo: Edições Loyola

PCP. Programa e Estatutos do Partido Comunista Português. Lisboa: Edições Avante, 1975.

PORTAS, Nuno (1986). O processo SAAL: entre o Estado e o Poder Local. Revista Crítica de Ciências Sociais. 18,19 e 20, 635-644

SANTOS, José Hipólito (2014). Sem mestres nem chefes o povo tomou a rua. Lutas dos moradores no pós-25 de Abril. Lisboa: Letra Livre.

SANTOS SILVA, A. (1990). Educação de Adultos. Educação para o desenvolvimento. Porto: Edições ASA.

SARDO, Delfim (2014). Espaços reais: o processo de uma utopia pragmática. In: Arquitetura e participação. Porto: Casa de Serralves, 25-42

SOUSA, Fernando e OLIVEIRA MARQUES, A. H, coords. (1982). Portugal e a Regeneração (1851-1900). Lisboa: Editorial Presença.

STOER, Steve (1986). Educação e mudança social em Portugal. 1970-1980, uma década de transição. Porto: Edições Afrontamento.

VEIGA, IVO (2002). O Boletim do MFA e o processo revolucionário português (Setembro de 1974 - Agosto 1975). Arquivos da Memória, no duplo 12/13

Recebido em 24 de maio de 2015. Aprovado em 13 de agosto de 2015. 